\title{
The Clinical Profile of Distal Third Femoral Shaft Fractures Patients
}

\author{
Dr. Mohammad Kamal Hossain ${ }^{*}$, Dr. Md. Nazmul Huda ${ }^{2}$, Dr. Md. Ashik Salauddin ${ }^{3}$, Md. Mizanur Rahman ${ }^{4}$, Dr. Md. Harun-Or-
} Rashid $^{5}$, Dr. Sayeda Begum Panna ${ }^{6}$, Dr. Md. Shafiqul Islam ${ }^{7}$

\footnotetext{
${ }^{1}$ Assistant Professor, Department of Orthopaedic Surgery, Chandpur Medical College, Chandpur, Bangladesh

${ }^{2}$ Assistant Professor, Department of Orthopaedic Surgery, Shaheed Suhrawardy Medical College, Dhaka, Bangladesh

${ }^{3}$ Junior Consultant, Department of Orthopaedic Surgery, 250 Beded General Hospital, Gopalgonj, Bangladesh

${ }^{4}$ Junior consultant, Department of Orthopedic surgery, Dhaka Medical college Hospital, Dhaka, Bangladesh

${ }^{5}$ Assistant Professor, Department of Surgery, Chandpur Medical College, Chandpur, Bangladesh

${ }^{6}$ Anaesthesiologist, National Institute of Diseases of Chest and Hospital, Mohakhali, Dhaka, Bangladesh

${ }^{7}$ Assistant Professor, Orthopaedic Surgery, Mugda Medical College, Mugda, Dhaka, Bangladesh
}

DOI: $10.36347 /$ sjams.2021.v09i03.021

| Received: 09.02.2021 | Accepted: 20.02.2021 | Published: 15.03.2021

*Corresponding author: Dr. Mohammad Kamal Hossain

Abstract

Original Research Article

Objective: In this study our main goal is to evaluate the clinical profile of distal third femoral shaft fractures patients. Method: This prospective observational study was carried out at National Institute of Traumatology and Orthopedic Rehabilitation (NITOR), Dhaka from June 2007 to December 2008. Where a total of 10 patients with distal femoral fractures were selected and treated with open reduction and internal fixation were included in the study. Result: During the study, most of the patients belong to 30-39 years age group and 80\% were male. Highest number of patients had right side involvement $(60 \%)$. (90\%) had sustained high-energy trauma while only $10 \%$ suffered lowenergy trauma. Also, 50\% were operated upon within 1-2 weeks of injury. Conclusion: From our result we can conclude that, most of the patients had right side involvement and majority had sustained high-energy trauma. Early surgery, closed reduction, at least two screws in each fragment and early post-operative knee mobilization are essential for good outcome in patients.

Keywords: Distal third femoral shaft fractures, knee joint, retrograde nailing.

Copyright $\odot 2021$ The Author(s): This is an open-access article distributed under the terms of the Creative Commons Attribution 4.0 International License (CC BY-NC 4.0) which permits unrestricted use, distribution, and reproduction in any medium for non-commercial use provided the original author and source are credited.

\section{INTRODUCTION}

The term 'distal femur' traditionally comprises the lower third of the femur. This zone is the literature varies greatly between the distal $7.6 \mathrm{~cm}$ and the distal $15 \mathrm{~cm}$ of the femur.

The supracondylar area of distal femur is the transition zone between the distal diaphysis and the femoral articular condyles. At the diaphysealmetaphyseal junction, the metaphysis flares, especially origin the medial side, to provide platform for the broad condylar weight-bearing surface of the knee joint. Anteriorly between this condyle is the smooth articular depression for patella '-I and posteriorly the intercondylar notch.

The femoral shaft gives attachment of different muscles and is subjected to major muscular forces that deform the thigh after a fracture. In fracture distal third of femur, the distal fragment may be held flexed by unopposed action of the gastrocnemius [1].
From one review found that available evidence for treatment options of distal femur fractures is insufficient to inform clinical practice and that there is a priority for a high-quality trial to be undertaken [2]. The incidence of malunion, non-union and infection are relatively high. Non operative treatment is consistently associated with poor results. Because of proximity to knee joint, full knee function may be difficult [3].

In this study our main goal is to evaluate the clinical status of distal third femoral shaft fractures patients.

\section{OBJECTIVE}

- To assess the clinical profile of distal third femoral shaft fractures patients.

\section{METHODOLOGY \\ Type of Study}

- This prospective observational study 
Mohammad Kamal Hossain et al; Sch J App Med Sci, Mar, 2021; 9(3): 398-400

\section{Place and Period Study}

- The study was carried out at-the National Institute of Traumatology and Orthopedic Rehabilitation (NITOR), Dhaka from June 2007 to December 2008.

\section{Study Population}

- 10 patients with distal femoral fractures were selected and treated with fin nailing. 8 patients were male and 2 patients were female. The mean age was 38.5 years (range 20-60 year). Six fractures were Winquist type I and four fractures were Winquist type II. Most of the fractures were high energy injuries caused by road traffic accidents.

\section{Sampling Method}

- Purposive sampling method was followed as per inclusion and exclusion criteria.

\section{Inclusion Criteria}

- Age: Adult patients i.e. fractures with distal epiphyseal fusion.

- Fracture: Distal femoral shaft only.

- Injury: Closed fractures only.

- Injury time: Fresh and less than three weeks old fractures were taken.

- Fracture type: Stable fractures i.e. Winquist type I and type II fractures.

\section{Data collection procedure:}

A pretested and predesigned proforma containing history and examination findings of the patient, operative procedure and follow up was used to collect the data.

\section{Data Analysis}

Data were collected, compiled and tabulated according to key variables. All statistical analysis of different variables were carried out according to standard statistical methods and calculations done by using scientific calculator.

\section{RESULTS}

In Table-1 shows age distribution of the patients where $40 \%$ patients belong to $30-39$ years' age group. The following table is given below in detail:
Table-1: Age distribution of the patients

\begin{tabular}{|l|l|l|}
\hline Age distribution of the patients & n & \% \\
\hline $20-29$ & 2 & 20 \\
\hline $30-39$ & 4 & 40 \\
\hline $40-49$ & 3 & 30 \\
\hline $50-60$ & 1 & 10 \\
\hline
\end{tabular}

Table-2 shows that out of 10 cases $8(80 \%$.) were male and $2(20 \%)$ were female. The male female ratio was 4 :

Table-2: Sex distribution of patients (IT-10)

\begin{tabular}{|l|l|l|}
\hline Sex & Number of patients & Percentage \\
\hline Male & 8 & 80 \\
\hline Female & 2 & 20 \\
\hline
\end{tabular}

In Table-3 shows distribution of side involvement $(: n=10)$ where highest number of patients had right side involvement $(60 \%)$. The following table is given below in detail:

Table-3: Distribution of side involvement

\begin{tabular}{|l|l|l|}
\hline $\begin{array}{l}\text { Side } \\
\text { involvement }\end{array}$ & $\begin{array}{l}\text { Number of } \\
\text { patients }\end{array}$ & Percentage \\
\hline Right & 6 & 60 \\
\hline Left & 4 & 40 \\
\hline
\end{tabular}

In Table-4 considering mechanism of injury, shows that the highest percentage $(90 \%$.) had sustained high-energy trauma while only $10 \%$ suffered lowenergy trauma. The following table is given below in detail:

Table-4: Mechanism of injury

\begin{tabular}{|l|l|l|}
\hline Mechanism of injury & n & \% \\
\hline High-energy trauma & 9 & 90 \\
\hline Motor vehicle accident & 5 & 50 \\
\hline Motor cycle accident & 2 & 20 \\
\hline Auto-pedestrain accident & 1 & 10 \\
\hline Fall from height & 1 & 10 \\
\hline Low energy trauma & 1 & 10 \\
\hline
\end{tabular}

Table-5 shows that 5 patients $(50 \%)$ were operated upon within 1-2 weeks of injury.

Table-5: Time interval between injury and operation

\begin{tabular}{|l|l|l|l|}
\hline Group & Time interval between injury and fixation (wk) & Number of patients & Percentage \\
\hline 1 & $<1$ & 2 & 20 \\
\hline 2 & $1-2$ & 5 & 50 \\
\hline 3 & $2-3$ & 3 & 30 \\
\hline
\end{tabular}

Table-5 of time interval between injury and fixation of fracture $(n=10)$ within 1-2 weeks of injury. The following figure is given below in detail:

In Figure-1 shows time interval between injury and fixation (wks) where $50 \%$ were operated upon 
Mohammad Kamal Hossain et al; Sch J App Med Sci, Mar, 2021; 9(3): 398-400

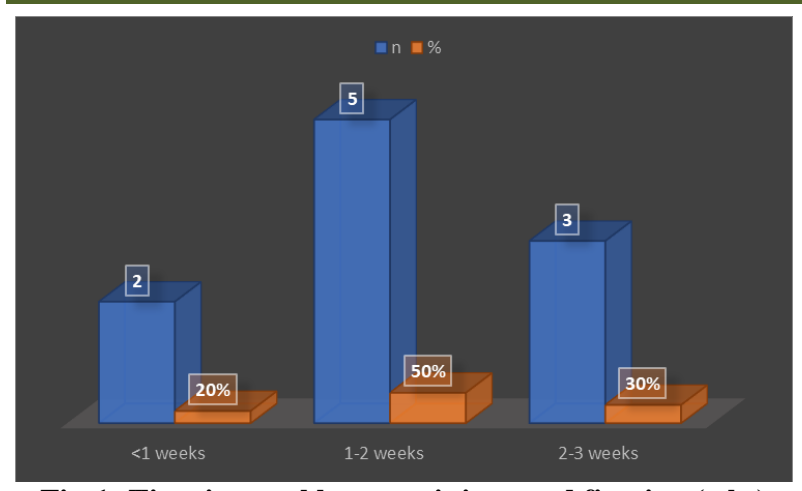

Fig-1: Time interval between injury and fixation (wks)

\section{DISCUSSION}

In the study, the age of the patients was between 20 to 60 years, mean age being 38.5 years. Almost similar findings were reported by two studies where the average age of the patients was 38 years and 39 years respectively $[4,5]$.

Total number of cases were 10 , among them 8 $(80 \%)$ were male and $2(20 \%)$ were female. Malefemale ratio was -+: 1 . In one study male-female ratio was $8: 3$ [4] \& in the another study, the male-female ratio was $6.5: 1.60 \%$ patients were affected on the right side and $40 \%$ patients were affected on the left side [5].

Analyzing the mechanism of injury, it was found that majority $(90 \%)$ of patients sustained injury due to high-energy trauma. Among $90 \%$ patients, 50\% patients sustained injury from Motor Vehicle Accident, $20 \%$ from motor cycle accidents and $10 \%$ due to autopedestrian accidents. Only $10 \%$ of distal femoral shaft fractures occurred due to low-energy trauma as a result of fall on the ground. Another study reported in study that $76 \%$ distal femoral fractures were due to high energy trauma [4].
All fractures united within average 16 weeks and were able to bear weight within 12 weeks of fixation. Period of fracture healing was average 22.4 weeks in the one study \& 18 weeks in the study of other study $[6,7]$.

\section{CONCLUSION}

From our result we can conclude that, most of the patients had right side involvement and majority had sustained high-energy trauma. Early surgery, closed reduction, at least two screws in each fragment and early post-operative knee mobilization are essential for treatment in patients.

\section{REFERENCES}

1. Wilson JN. Fractures and Joint Injuries; Sixth ed; 1996; pp 1003-04.

2. Stewart MJ, Sisk TD, Wallace SL. Fractures of distal third of femur -a compression method of treatment. JBJS, 1966 June; 48-A, 784-807.

3. Tornetta P 3rd, Tibuzi D. Antegrade or retrograde reamed femoral nailing. A prospective randomized trial. J Bone Joint Surg (Br). 2000; 82(5):652-4.

4. Ricci WM. Bellabarba C, Lewis R, Evanoff B, Herscovice D, Dipasquale T, Sanders R. Retrograde versus antegrade nailing of femoral shaft fractures. J Orthop Trauma. 2001; 15(2):9095.

5. Lewis GZ. "SIGN" Manual of IM Nail Insertion \& Extraction, 2001; pp H-17.

6. Ostrum RF, Agarwal A, Laxatos R, Poka A. Prospective comparison of retrograde and antegrade femoral Intramedullary nailing J Orthop Trauma. 2000;14(7):496-501.

7. Kettlkamp DB, DeRosa GP. Biomechanics and functional role of the patellofemoral joint. AAOS Instr Course Leet, 1976; 25-27. 